\title{
Desenvolvimento de Novos Catalisadores para a Produção de Biodiesel
}

\author{
J. F. Puna ${ }^{1}$, J. F. Gomes ${ }^{1,2}$, J. C. Bordado ${ }^{2}$
}

São descritos trabalhos preliminares sobre o desenvolvimento de novos catalisadores metálicos heterogéneos para a produção de biodiesel por transesterificação de triglicéridos. Actualmente, esta reacção com metanol é catalisada de forma homogénea, por exemplo, com $\mathrm{NaOH}$ ou $\mathrm{KOH}$. Este tipo de catalisadores é corrosivo para os equipamentos, tendo que ser neutralizados após a reacção, originando-se, assim, correntes salinas liquidas. Além disso, originam uma série de operações de separação que poderão ser obviadas pela utilização de catalisadores heterogéneos que não originam correntes nem resíduos poluentes.

\section{INTRODUÇÃO}

São considerados biocombustíveis as substâncias combustíveis produzidas a partir da biomassa e neles se incluem o biodiesel (monoalquiléster de ácidos gordos - FAME), o bioálcool (etanol) e o biogás (mistura de metano e $\mathrm{CO}_{2}$ ).

O sector dos transportes rodoviários é, a nível mundial, 98\% dependente do petróleo. Na UE este sector é responsável por mais de $20 \%$ das emissões totais de $\mathrm{CO}_{2}$, sendo mais de $50 \%$ dessas emissões devidas ao transporte rodoviário particular, que desde 1999 aumentou 22\%.

As alterações climáticas, o aumento do preço do petróleo e a segurança do abastecimento energético conduziram ao crescente interesse sobre a utilização dos biocombustíveis como substitutos dos carburantes derivados do petróleo [1].

Actualmente, o biodiesel é essencialmente produzido a partir de plantas oleaginosas por um processo de transesterificação (ver Figura 1), envolvendo álcool (essencialmente metanol, $\mathrm{CH}_{3} \mathrm{OH}$ ) e um catalisador, preferencialmente alcalino, de fase líquida, sendo, por isso, considerado um processo de catálise homogénea.

As principais matérias-primas são maioritariamente os óleos, previamente refinados, de colza, girassol e soja.

${ }^{1}$ Departamento de Engenharia Química, ISEL, R. Cons. Emídio Navarro, 1, 1950-062 Lisboa Centro de Engenharia Química e Biológica - CEQB

Quimicamente, o biodiesel é descrito como uma mistura de ésteres metílicos de ácidos gordos (ésteres mono, di e triglicéridos). A glicerina, subproduto da reacção de transesterificação, pode ser utilizada na indústria farmacêutica e cosmética $[1,2]$<smiles>[R]C(=O)OCC(COC([R])=O)OC([R])=O</smiles><smiles>C#CCOC(=O)C(CO)CO</smiles>

Figura 1 Reacção de transesterificação para produção de biodiesel

Para a adequada introdução no mercado, o biodiesel deve obedecer a determinadas especificações. Naturalmente que a matéria-prima afecta consideravelmente os requisitos do processo de fabrico e as especificações finais do biocombustível.

De referir que, para garantir as referidas especificações, o processo de produção de biodiesel tem de ser muito bem controlado, quer ao nível do controle reaccional, quer, sobretudo, ao nível dos processos de separação biodiesel/metanol, biodiesel/ catalisador e biodiesel/água, no processo de lavagem do biocombustível.

Um dos parâmetros mais importantes nas especificações é o teor máximo de glicerina total, que é de $0,25 \%$ nas normas europeias e americanas, de modo a evitar a formação de depósitos na câmara de combustão e a produção de teores elevados de acroleína nos gases de escape dos veículos automóveis [2].

Outros parâmetros importantes são a viscosidade, o teor de água, o índice de iodo, o teor de mono, di e triglicéridos, o teor de metanol, o teor de enxofre, cinzas, resíduo carbonoso, contaminação total e número de cetano. As especificações do biodiesel actualmente consideradas baseiam-se na norma EN 14214.

A Tabela 1 apresenta as metas estipuladas pela UE para a incorporação de biocombustíveis nos combustíveis fósseis até 2010 , onde se inclui a incorporação do biodiesel no gasóleo [3].

Tabela $\mathbf{1}$ Metas comunitárias
para a incorporação de biocombustíveis
nos combustíveis fósseis [3]
\begin{tabular}{|c|c|c|c|c|}
\hline $\mathbf{2 0 0 5}$ & $\mathbf{2 0 0 6}$ & $\mathbf{2 0 0 7}$ & $\mathbf{2 0 0 9}$ & $\mathbf{2 0 1 0}$ \\
\hline $2 \%$ & $2,75 \%$ & $3,5 \%$ & $5 \%$ & $5,75 \%$ \\
\hline
\end{tabular}

A Figura 2 apresenta, de forma esquemática, o processo de produção de biodiesel. 


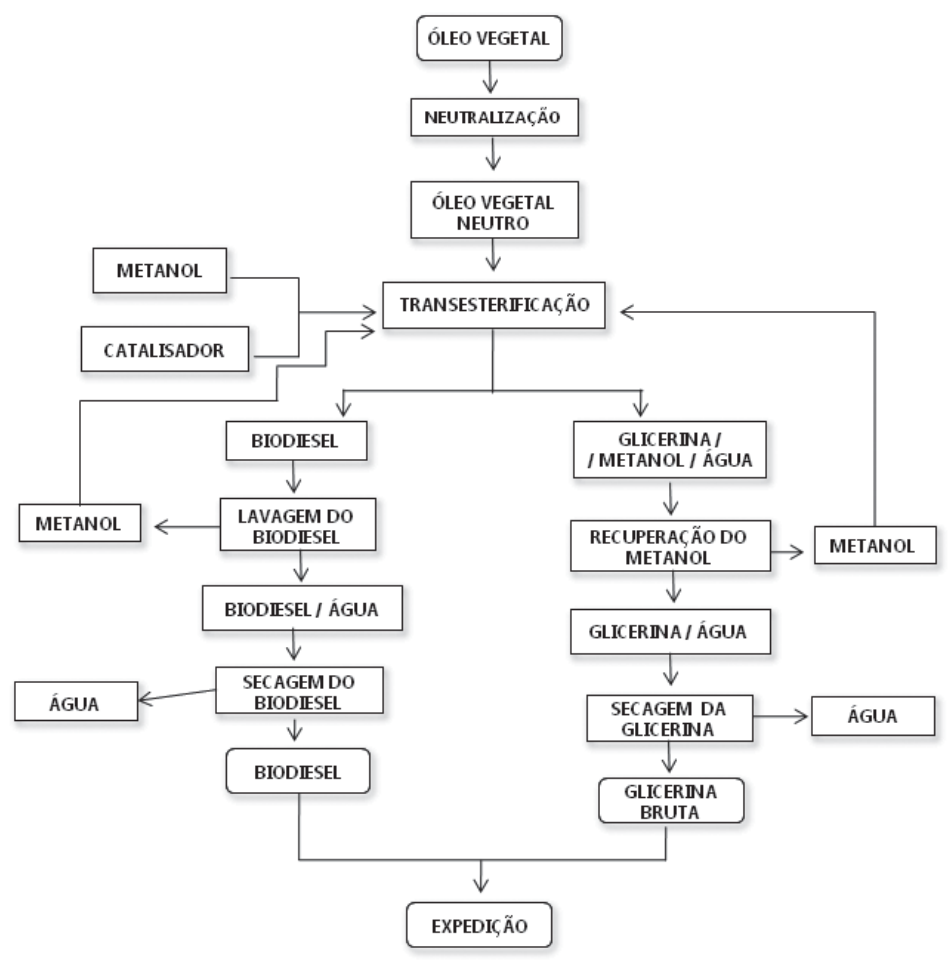

Figura 2 Diagrama processual esquemático do processo de produção de biodiesel

\section{Desenvolvimento de Novos Catalisadores Heterogéneos para a Produção de Biodiesel}

A transesterificação é o processo tecnicamente mais eficiente e mais viável para a produção de biodiesel em larga escala, com minimização de subprodutos, desde que as matérias-primas mantenham um nível mínimo de qualidade. Este processo pode ser conduzido na presença de catalisadores ácidos, básicos e enzimáticos, simples ou complexos. O emprego de catalisadores ácidos, como o ácido sulfúrico, leva a uma cinética da reacção muito lenta quando comparada com os catalisadores alcalinos. Outro inconveniente na utilização dos catalisadores ácidos tem a ver com a sua remoção do biodiesel, visando prevenir possíveis danos às partes integrantes dos motores.

A catálise básica é, pelo contrário, muito rápida, atingindo-se normalmente o estado estacionário ao fim de 15 minutos e com excelentes rendimentos, muitas vezes superiores a $90 \%$. No entanto, tem o inconveniente de ser sensível à presença de água e de ácidos gordos livres, os quais consomem o catalisador e levam à formação de géis e sabões. Tais constrangimentos dificultam a utilização de óleos usados de frituras. Por outro lado, os catalisadores enzimáticos oferecem vantagens relativamente aos catalisadores ácidos e alcalinos, como sejam a menor sensibilidade à água, a recuperação do catalisador e a sua separação do biodiesel. No entanto, apresenta custos elevados [2].

Para fazer face às dificuldades encontradas com a utilização dos actuais e convencionais catalisadores homogéneos alcalinos ou ácidos, nomeadamente, nos processos de separação biodiesel/catalisador, começa a ser empregue uma linha alternativa de catalisadores sólidos, daí designar-se por catálise heterogénea. Por outro lado, estas soluções alternativas e inovadoras de produção de biodiesel permitem rentabilizar economicamente o processo produtivo, tornando-o mais competitivo e também mais sustentável do ponto de vista ambiental. Neste aspecto, a utilização de sistemas catalíticos heterogéneos para a transesterificação dos triglicéridos em biodiesel implicará a eliminação de diversos processos de lavagem/recuperação do catalisador e do próprio biodiesel, permitindo assegurar uma maior eficiência e rentabilidade do processo, baixando os seus custos de produção, havendo ainda a possibilidade de poder ser implementado em regime de funcionamento contínuo processual.

A utilização de catalisadores heterogéneos conduz a um aumento do tempo de duração do catalisador, pois não é necessário recirculação deste, nem regeneração do estado inicial do mesmo, visto que o tempo de utilização será claramente superior aos processos convencionais de catálise homogénea, acarretando menos substituições no reactor, o qual será, necessariamente, de leito fixo catalítico. Tal facto implicará maior qualidade do produto final e do produto secundário, a glicerina. No entanto, quer o grau de conversão da reacção, quer o "turnover number" 1 para poderem ser mantidos, terão de se optimizar as condições operatórias do reactor. De referir ainda que, ajustando o caudal de reagentes para valores adequados, é possível maximizar a conversão da reacção, de tal modo que o tempo de contacto com o leito catalítico seja o mais adequado possível para atingir este fim.

Realizando uma breve pesquisa bibliográfica sobre o que já foi efectuado nesta matéria, destacam-se várias contribuições, as quais estão sintetizadas na Tabela 2. Está em curso o estudo da performance catalítica de catalisadores como óxidos alcalinos, aluminatos e estruturas híbridas básicas com metais, para se poderem seleccionar as estruturas catalíticas com mais actividade. Os catalisadores em causa serão sais metálicos de aminoácidos, tais como, zincoarginato, níquelarginato, adequados à catálise da metanólise de trialquilgliceróis. Os arginatos serão heterogeneizados utilizando substratos orgânicos, tais como polímeros, membranas e grânulos gerados por polimerização em emulsão.

A optimização deste processo à escala industrial, passará pelo estudo prévio, em laboratório, da variação das razões de concentração, temperatura, forma e composição dos catalisadores e tempo de residência num reactor catalítico de leito fixo. Pretende-se a posteriori, optimizar um processo à escala piloto de uma unidade processual de produção de biodiesel com catalisador heterogéneo e determinar a sua pureza comparando com as especificações constantes da norma EN 14214. 
Tabela 2 Catalisadores heterogéneos utilizados, condições experimentais e respectivos resultados reportados em literatura, para a produção de biodiesel

\begin{tabular}{|c|c|c|}
\hline Autores (ano) & Catalisadores utilizados e propriedades & Condições experimentais e resultados obtidos \\
\hline $\begin{array}{l}\text { Kiss et al. } \\
(2006)\end{array}$ & $\begin{array}{l}\text { Zeólitos } \mathrm{Y}, \beta \text { e } \mathrm{ZSM}-5 \text {, Resinas catiónicas } \\
\text { Amberlyst- } 15 \text { e Nafion-50, óxidos } \\
\text { metálicos como } \mathrm{ZrO}_{2} / \mathrm{SO}_{4}^{2-}, \mathrm{TiO}_{2} / \mathrm{SO}_{4}{ }^{2-} \\
\quad \text { e } \mathrm{SnO}_{2} / \mathrm{SO}_{4}{ }^{2-} \text { e } \mathrm{Cs}_{2,5} \mathrm{H}_{0,5} \mathrm{PW}_{12} \mathrm{O}_{40}\end{array}$ & $\begin{array}{l}\text { Bons resultados de conversão reaccional e rendimento obtidos } \\
\text { para } \mathrm{ZrO}_{2} / \mathrm{SO}_{4}^{2-} \text { numa vasta gama de temperaturas. }\end{array}$ \\
\hline $\begin{array}{l}\text { Rosa et al. } \\
\text { (2005) }\end{array}$ & $\begin{array}{l}\text { Ácido butilestanóico }\left(\left(\mathrm{C}_{4} \mathrm{H}_{9}\right) \mathrm{SnO}(\mathrm{OH})\right) \text {, } \\
\text { óxido de dibutilestanho }\left(\left(\mathrm{C}_{4} \mathrm{H}_{9}\right)_{2} \mathrm{SnO}\right) \\
\text { e dibutil dilaurato de estanho } \\
\qquad\left(\left(\mathrm{C}_{4} \mathrm{H}_{9}\right)_{2} \mathrm{Sn}\left(\mathrm{C}_{12} \mathrm{H}_{23} \mathrm{O}_{2}\right)_{2}\right)\end{array}$ & $\begin{array}{l}\text { Transesterificação do óleo de soja. Rácio molar óleo/ metanol/ } \\
\text { catalisador: 100/400/1, } 10 \text { h de tempo reaccional. Maior } \\
\text { conversão (35\%) para o óxido de dibutilestanho. }\end{array}$ \\
\hline $\begin{array}{l}\text { Srivastava } \\
\text { et al. (2006) }\end{array}$ & $\begin{array}{l}\text { Catalisadores de Fe-Zn suportados em } \\
\text { complexos cianídricos, sem e com terc- } \\
\text {-butanol (agente complexante) e com um } \\
\text { copolímero }\left(\mathrm{EO}_{20} \mathrm{PO}_{70} \mathrm{EO}_{20}\right)\end{array}$ & $\begin{array}{l}\text { Maior actividade e selectividade com agente complexante na } \\
\text { matriz catalítica. }\end{array}$ \\
\hline $\begin{array}{l}\text { Perin et al. } \\
\text { (2006) }\end{array}$ & $\begin{array}{c}\mathrm{SiO}_{2} / \mathrm{H}_{2} \mathrm{SO}_{4}, \mathrm{SiO}_{2} / \mathrm{KOH} \text { e Al } \mathrm{O}_{3} / \mathrm{KOH} \\
\mathrm{SiO}_{2} / \mathrm{HCl}, \mathrm{SiO}_{2} / \mathrm{ZnCl}_{2}, \mathrm{SiO}_{2} / \mathrm{AlCl}_{3} \mathrm{e} \\
\mathrm{Al}_{2} \mathrm{O}_{3} / \mathrm{H}_{2} \mathrm{SO}_{4}\end{array}$ & $\begin{array}{l}\text { Transesterificação do óleo de mamona e de soja, com metanol, } \\
\text { temperaturas de } 25^{\circ} \mathrm{C} \text { e } 65^{\circ} \mathrm{C} \text {, rácio suporte/catalisador de } \\
50 \%(\mathrm{~m} / \mathrm{m}) \text {, rácio óleo/metanol de } 1: 6 \text {, rácio mássico de } \\
5 \mathrm{~g} \text { óleo } / 0,25 \mathrm{~g} \text { de catalisador. Melhores resultados para } \\
\text { catalisadores suportados de alumina para catálise alcalina, } \\
\text { enquanto que a sílica apresentou melhores resultados para } \\
\text { catálise ácida. }\end{array}$ \\
\hline $\begin{array}{l}\text { Rosa et al. } \\
\qquad(2007)\end{array}$ & $\mathrm{K}_{2} \mathrm{CO}_{3}, \mathrm{Na}_{2} \mathrm{CO}_{3} \mathrm{e} \mathrm{CaCO}_{3}$ & $\begin{array}{l}\text { Transesterificação do óleo de mamona, com metanol; rácio } \\
\text { óleo/ metanol/ catalisador de 100/600/1, tempo reaccional } \\
\text { de } 10 \text { h. } \mathrm{O} \mathrm{K}_{2} \mathrm{CO}_{3} \text { apresentou melhor actividade catalítica e } \\
\text { maiores rendimentos na obtenção de biodiesel. } \mathrm{CaCO}_{3} \text { não } \\
\text { apresentou qualquer actividade catalítica. }\end{array}$ \\
\hline $\begin{array}{l}\text { Brito et al. } \\
\text { (2007) }\end{array}$ & Zeólito Y & $\begin{array}{l}\text { Utilização de óleos usados de frituras. Bons resultados em } \\
\text { termos de rendimento de biodiesel. }\end{array}$ \\
\hline $\begin{array}{l}\text { West et al. } \\
\text { (2007) }\end{array}$ & $\mathrm{ZrO}_{2} / \mathrm{SO}_{4}{ }^{2-}$ & $\begin{array}{l}\text { Bons resultados em termos de actividade do catalisador e de } \\
\text { rendimento do biodiesel. }\end{array}$ \\
\hline $\begin{array}{l}\text { Santos et al. } \\
\qquad(2007)\end{array}$ & $\begin{array}{l}\text { Hidrotalcites de magnésio e alumínio } \\
\text { (rácio } \mathrm{Mg} / \mathrm{Al} \text { de } 3 \text { ), modificadas com } \\
\mathrm{Zn}, \mathrm{Sn}, \mathrm{Ba}, \mathrm{Mn}, \mathrm{Ce} \text { e Ca, com } 5 \% \\
\text { catalisador }(\% \mathrm{~m} / \mathrm{m})\end{array}$ & $\begin{array}{l}\text { Transesterificação do óleo de soja com metanol, } 70^{\circ} \mathrm{C} \text {, } \\
\text { tempo reaccional de } 3 \mathrm{~h} \text {, rácio metanol/óleo de } 9: 1 \text {. Bons } \\
\text { resultados obtidos em termos de rendimento e qualidade final } \\
\text { do biodiesel. }\end{array}$ \\
\hline
\end{tabular}

\section{Conclusões}

Nesta primeira abordagem, pode-se concluir que as vantagens da substituição dos actuais catalisadores homogéneos por matrizes catalíticas heterogéneas (sólidas), constituem mais-valias do ponto de vista processual, económico e ambiental, em que este último aspecto deriva da minimização da produção de resíduos e de efluentes no processo de fabrico. Por outro lado, pode-se constatar, de entre os resultados experimentais encontrados na pesquisa bibliográfi- ca efectuada que, quer a actividade catalítica, quer os rendimentos de biodiesel obtidos, quer a qualidade do biocombustível (cumprimento dos requisitos de qualidade constantes na norma EN 14214) foram maximizados com matrizes de catalisadores metálicos suportados, principalmente a de $\mathrm{ZrO}_{2} / \mathrm{SO}_{4}{ }^{2-}$, para várias temperaturas, preferencialmente, mais elevadas, na ordem dos 65 a $70^{\circ} \mathrm{C}$, com quantidades de metanol seis vezes superiores à dos óleos utilizados e com teores de $1 \%$ de catalisador relativamente ao óleo usado no processo de transesterificação.
NotA

1 Define-se turnover number como a quantidade de substrato convertida por quantidade de catalisador.

\section{REFERÊNCIAS}

[1] "Biodiesel and Sustainable Development", Ingenium, II ${ }^{\text {nd }}$ Series, 99(2007) 53.

[2] "Strategic Issues Department of Brazilian Republic Presidency”, Biofuels, NAE copy-book - long term strategically process, 2 (2004) 83-94.

[3] L. Pelkmans, K. Govaerts, E. Bekiaris, E. Portouli, P. Georgopoulos, "Euro- 
pean Biofuels Strategy", International Journal of Environmental Studies 64(3) (2007) 325-346.

[4] A. Kiss, F. Omota, A. Dinien, G. Rotherburg, "The heterogeneous advantage: Biodiesel by catalytic reactive distillation", Topics in Catalysis, 40 (1-4) (2006) 141-150.

[5] M. Rosa, A. Oliveira, "Sinthethyzation of Biodiesel by Tin (IV) complexes", Proceedings of the 3rdBrazilian Congress of Petroleum and Gas - IBP, Brazil, 2005.

[6] R. Srivastava, D. Srinivas, P. Ratnasanry, "Fe-Zn doubles metal cyanide complexes as novel, solid transesteri- fication catalysts", Journal of Catalysis, 241 (2006) 34-44.

[7] D. Perin, W. Armareg, P. Perrin, "Heterogeneous Catalysis in the transesterification of mamona and soy oils", Proceedings of $29^{\text {th }}$ Annual Reunion of Chemical Brazilian Society, Brazil, 2006.

[8] M. Rosa, A. Oliveira, "Carbonates utilization as heterogeneous catalysts of transesterification", Proceedings of $29^{\text {th }}$ Annual Reunion of Chemical Brazilian Society, Brazil, 2006.

[9] A. Brito, M. Borges, R. Arvelo, F. Garcia, M. Diaz, N. Otero, "Reuse of Fried Oil to Obtain Biodiesel: Zeolites $\mathrm{Y}$ as a Cata-
Iyst", International Journal of Chemical Reactor Engineering, 5 (2007) Article A104.

[10] A. West, D. Posarak, N. Ellis, "Simulation, Case Studies and Optimization of a Biodiesel Process with a Solid Acid Catalyst", International Journal of Chemical Reactor Engineering, $\mathbf{5}$ (2007) Article A37.

[11] A. Santos, "Heterogeneous Catalysts for Biodiesel production - Metanolysis of Soy Oil over Hidrotalcytes of Magnesium and Aluminium changed", Master Thesis of Environmental Engineering, IST/UTL, Lisbon, 2007.

\section{Actualidades Científicas}

\section{Procura de silício para células FOTOVOLTAICAS EM ALTA}

Em princípios de Agosto, a Evonik e SolarWorld anunciaram a abertura de uma fábrica de produção de silício «solar» em Rheinfelden, na Alemanha, como parte do consórcio Joint Solar Silicon. As empresas dizem que o seu processo de produção de filmes ultra-finos de silício permite uma economia de até $90 \%$ em relação à energia utilizada nos processos de produção convencionais. A nova fábrica terá uma capacidade de produção de 850 toneladas de silício "solar» por ano e a matéria-prima será fornecida pela fábrica de silano $\left(\mathrm{SiH}_{4}\right)$ da Evonik.

As células fotovoltaicas de filme fino, embora com uma eficiência em laboratório inferior à das células de primeira geração, frequentemente permitem melhores resultados em comparação com as células clássicas nas aplicações reais do dia-a-dia, devido a perdas inferiores às temperaturas elevadas de funcionamento e a uma melhor eficiência em condições de baixa intensidade de luz. No entanto, o crescimento da fatia de mercado destas células tem sido limitado pela sua baixa disponibilidade no mercado. Assim, ambas as notícias são excelentes já que as células convencionais dominam por enquanto o mercado das fotovoltaicas e a falta de silício monocristalino no mercado tem limitado o crescimento do sector e aumentado muito o preço deste material e, consequentemente, dos painéis solares.

PS

\section{Prémio Nobel da Medicina 2008}

O Prémio Nobel da Medicina de 2008, atribuído pelo Karolinska Institute, foi repartido entre Harald zur Hausen, pela descoberta do vírus do papiloma humano (VPH ou HPV), causador do cancro cervical, e, conjuntamente, Françoise Barré-Sinoussi e Luc Montagnier, pela descoberta do vírus da imunodeficiência humana ( $\mathrm{VIH}$ ou HIV). Harald zur Hausen nasceu em 1936 na Alemanha, foi Director Científico do Centro Alemão de Investigação do Cancro (German Cancer Research Centre), em Heidelberg, Alemanha, onde é Professor Jubilado. Adoptando uma posição contrária ao que se pensava nos anos de 1970, postulou que o vírus do papiloma humano seria o causador do cancro cervical, o segundo tipo de cancro mais comum nas mulheres. A sua descoberta conduziu à caracterização da história natural da infecção pelo HPV, do mecanismo da carcinogénese induzida pelo HPV e ao desenvolvimento de vacinas profilácticas contra este tipo de cancro. Mais de $5 \%$ de todos os tipos de cancro a nível mundial são causados por infecções persistentes com este vírus. A infecção com o vírus do papiloma humano é o agente mais comum de transmissão sexual, afectando $50 \%$ a $80 \%$ da população. O trabalho desenvolvido por Harald zur Hausen permitiu que se compreendessem os mecanismos para a carcinogénese induzida pelo vírus do papiloma e os factores predisponentes para a persistência viral e a transformação celular. Estes estudos permitiram que fossem descobertas vacinas que conferem protecção superior a 95\% em relação a dois tipos de HPV. Françoise Barré-Sinoussi e Luc Montagnier descobriram o vírus da imunodeficiência humana (HIV). Françoise Barré-Sinoussi nasceu em França em 1947. É professor e director da Unidade de Regulação de Infecções por Retrovírus, no Departamento de Virologia do Instituto Pasteur, em Paris. Luc Montagnier nasceu em 1932 em França. É Professor Jubilado e Director da Fundação Mundial para a Pesquisa e Prevenção da SIDA (World Foundation for AIDS Research and Prevention) em Paris. Em 1981 surgiram os primeiros relatórios médicos de um novo síndroma de imunodeficiência. A produção de vírus foi identificada em linfócitos de pacientes com nodos linfáticos inchados em estágios iniciais de imunodeficiência adquirida e em sangue de doentes em estágios mais avançados da doença. Françoise Barré-Sinoussi e Luc Montagnier isolaram e caracterizaram este vírus HIV que afecta o sistema imunitário devido à sua replicação massiva e danos celulares dos linfócitos. Após a descoberta do HIV, vários grupos contribuiram para demonstrar que este vírus estava na origem da síndroma da imunodeficiência humana adquirida (AIDS ou SIDA). Foi possível desenvolver métodos de diagnóstico de pacientes infectados e vários tipos de medicamentos antivirais. A combinação de prevenção e tratamento permitiu reduzir substancialmente a propagação da doença e aumentar a esperança de vida de doentes em tratamento. $\mathrm{O}$ vírus foi provavelmente transmitido por chimpanzés a humanos na África Ocidental no início do século $\mathrm{XX}$, mas ainda não está claro porque razão esta epidemia se propagou tão dramaticamente a partir dos anos de 1970. (Adaptado do "Press Release" de nobelprize.org) JM 